\title{
Impact of Screencast Technology: Connecting the Perception of Usefulness and the Reality of Performance
}

\author{
Katie R. Green, ${ }^{a}$ Tershia Pinder-Grover, ${ }^{b}$ \\ AND JOANNA Mirecki MillunCHiCK ${ }^{b}$ \\ ${ }^{a}$ Michigan State University, ${ }^{b}$ University of Michigan
}

\begin{abstract}
BACKGROUND
Prior research on the instructional use of screencasts (video of a computer screen output with realtime audio commentary) suggests that this technology is perceived by students as beneficial and results in improved course performance.
\end{abstract}

Purpose

This study explores how and why students use screencasts, as well as why some students choose not to use them. The study also investigates whether the perception that screencasts are helpful aligns with the reality of students' course performance.

\section{DESIGN/MeTHOD}

A quantitative study was conducted throughout two semesters in an undergraduate engineering survey course at a large public university. The investigation used a student perceptions survey and case study analysis to explore the connection between screencast use, the perception of having gained a deeper understanding of the course material based on this use, and actual course performance.

\section{RESULTS}

Findings indicate that students' preferred strategies for using screencasts are related to the frequency of use and the degree of understanding. Students who use the screencasts more and perceive them to have increased their understanding demonstrate increased competence on particular exam questions. Only those students who actively chose not to use screencasts (compared to those who forgot or ran out of time) show no detrimental effects on their performance.

\section{CONCLUSION}

Our findings highlight both the perceived and actual value of screencasting to students and the ways this technology is used. This research suggests that screencasting may promote self-efficacy among undergraduate engineering students.

\section{KEYWORDS}

screencasts, student perceptions, student performance

\section{INTRODUCTION}

The advent of simple software tools for developing screencasts - videos that capture computer screen output with concurrent audio commentary - has enabled their use in a variety of contexts. Screencasts are easy to create using a wide variety of software packages, ranging from rudimentary freeware to sophisticated proprietary software. They may be published as 
Flash movies, mpeg4 files, or other formats that can be read by personal computers, smart phones, tablet computers, and other devices. Originally, this technology was used to create tutorials for demonstrating the operation of new software tools, but educators have recently begun to adopt screencasts to enhance student learning (Betty, 2009; Bongey, Cizadlo \& Kalnbach, 2006; Brown-Sica, Sobel \& Pan, 2009; Copley, 2007; Cramer, Collins, Snider \& Fawcett, 2006; Falconer, deGrazia, Medlin \& Holmberg, 2009; Gardner \& Jeon, 2010; Grabe \& Christopherson, 2008; McGarr, 2009; McGrann, 2005; Zhu \& Bergom, 2007).

Screencasts used in the classroom can take the form of recorded lectures (Dey, Burn \& Gerdes, 2009) or supplementary resources such as shorter mini-lectures, explanations of homework, or exam solutions (Lee, Pradhan \& Dangarno, 2008). Screencasts have been developed for online courses, and five instructional approaches have been identified for these teaching tools: providing an overview, describing procedures, presenting concepts, elaborating on content, and focusing attention (Sugar, Brown \& Luterbach, 2010). Prior research on screencasts used by instructors to elaborate content has suggested that they can be a useful resource for students (Harpp et al., 2009; Hove \& Corcoran, 2008; Pinder-Grover et al., 2009a; Pinder-Grover et al., 2009b; Pinder-Grover, Green \& Millunchick, 2011).

Several studies also showed that students perceive screencasting as beneficial (Evans, 2011; Falconer et al., 2009, Harpp et al., 2009, Pinder-Grover et al., 2009a; Pinder-Grover et al., 2009b; Pinder-Grover et al., 2011) though not as a substitute for instructor-student interaction (Rose, 2009). For instance, Evans (2011) and Falconer et al. (2009) created screencasts in an embryology and a chemical engineering course, respectively. In both cases, students had favorable impressions of screencasts as an educational tool. Evans (2011) showed a positive impact on student performance with their use. Our past research examined student use of screencasts in a large and academically diverse introductory lecture course, Introduction to Materials and Manufacturing. Two types of screencasts were used: screencasts that presented the solutions to homework assignments (Millunchick, 2009) and mini-lecture screencasts that further explained concepts that students had identified as unclear (Millunchick, 2008). Results indicated that students perceived screencasting as both as helpful and leading to demonstrable improvements in course performance, especially for those who enter with the least amount of exposure to the subject matter (Pinder-Grover et al., 2011).

In addressing the need to further understand how and why students use these resources, our current research finds that students' preferred strategies for using homework solutions and mini-lecture screencasts are related to the frequency of use and degree of understanding regarding course material. Using quantitative analysis, we show that students who use the screencasts more and perceive them to have increased their understanding of the course material actually demonstrate increased competence in terms of higher performance. This is particularly true for students seeing the concepts for the first time. We measured performance based on students' overall course grades and their grades on particular exam questions. Finally, we examined students' reasons for not using screencasts in relation to their course performance and determined that only those students who actively chose not to use a screencast (compared to those who simply forgot or ran out of time) showed no detrimental effects in their performance. Our research had three specific questions: How do students use the screencasts and perceive their helpfulness? Do students' perceptions of screencasts helpfulness match the reality of their performance? Given the benefits of screencast use, why would students choose not to use them? 


\section{MeTHODS}

Data for the analyses came from a variety of sources (e.g., usage, student demographics, and course grades) and were gathered over several semesters during which the authors investigated the usefulness and impact of screencasts as tools for student learning.

\section{Data Sources}

This study examined students' use and perceptions of screencasts using data from the Fall 2008 and Winter 2009 terms. Every effort was made to keep the course the same between the semesters, including consistency in syllabus, instructor, textbook, lecture notes, and homework assignments. Each semester, the course as a whole was evaluated via student feedback at midterm and end of term. In addition to data collected from these course evaluations, students were invited to complete an IRB-approved online survey designed to gauge how students used the screencasts and perceived their helpfulness. A variety of student information was also gathered (e.g., demographic and screencast usage data) for each semester in order to investigate relationships between these factors and performance in the course. The registrar's office provided information pertaining to race/ethnicity, gender, citizenship, academic level, major, GPA, and SAT/ACT scores for each student. The course management Web site recorded usage data for all students enrolled in the class, including information on which screencasts were viewed by which students and when they were accessed; however, information was not available for how long each resource was used. The course instructor provided all performance data, including final course grade and scores on particular exams and exam questions, homework assignments, and quizzes.

\section{Data Collection Procedure}

Most data was relatively easy to obtain in electronic format by submitting requests to the registrar, course instructor, and administrator of the course management Web site. Demographic data were available from the registrar at the start of the semester, and usage and performance data were available at the close of the semester. The IRB-approved online survey was administered at the end of each semester but before the final exam so that final course grades would not influence students' responses. These surveys were completely voluntary with no monetary or material incentives received for participation. All analyses of the demographic, performance, and survey data were conducted after the semester's end and final grades were posted in order to preserve the students' anonymity during the course.

\section{Perceptions Measures}

The online survey sought to assess student use and perceptions of screencasts: how and why students used the screencasts, their helpfulness in general, and whether they assisted students in attaining a deeper understanding of the course material. Several measures were obtained from the survey data, including ordinal and categorical variables. More specifically, the perceived helpfulness of homework solution and mini-lecture screencasts was measured with responses to the questions listed in Figure 1. Students were also asked if they gained a deeper understanding of the course material based on use of the screencasts. Using a four-point Likert scale ( 1 = strongly disagree, 2 = disagree somewhat, 3 = agree somewhat, 4 = strongly agree), students rated their agreement with the statement "I have a deeper understanding of the material because of the homework solution/mini-lecture screencasts." Particularly noteworthy are our analytic measures that capture students' 


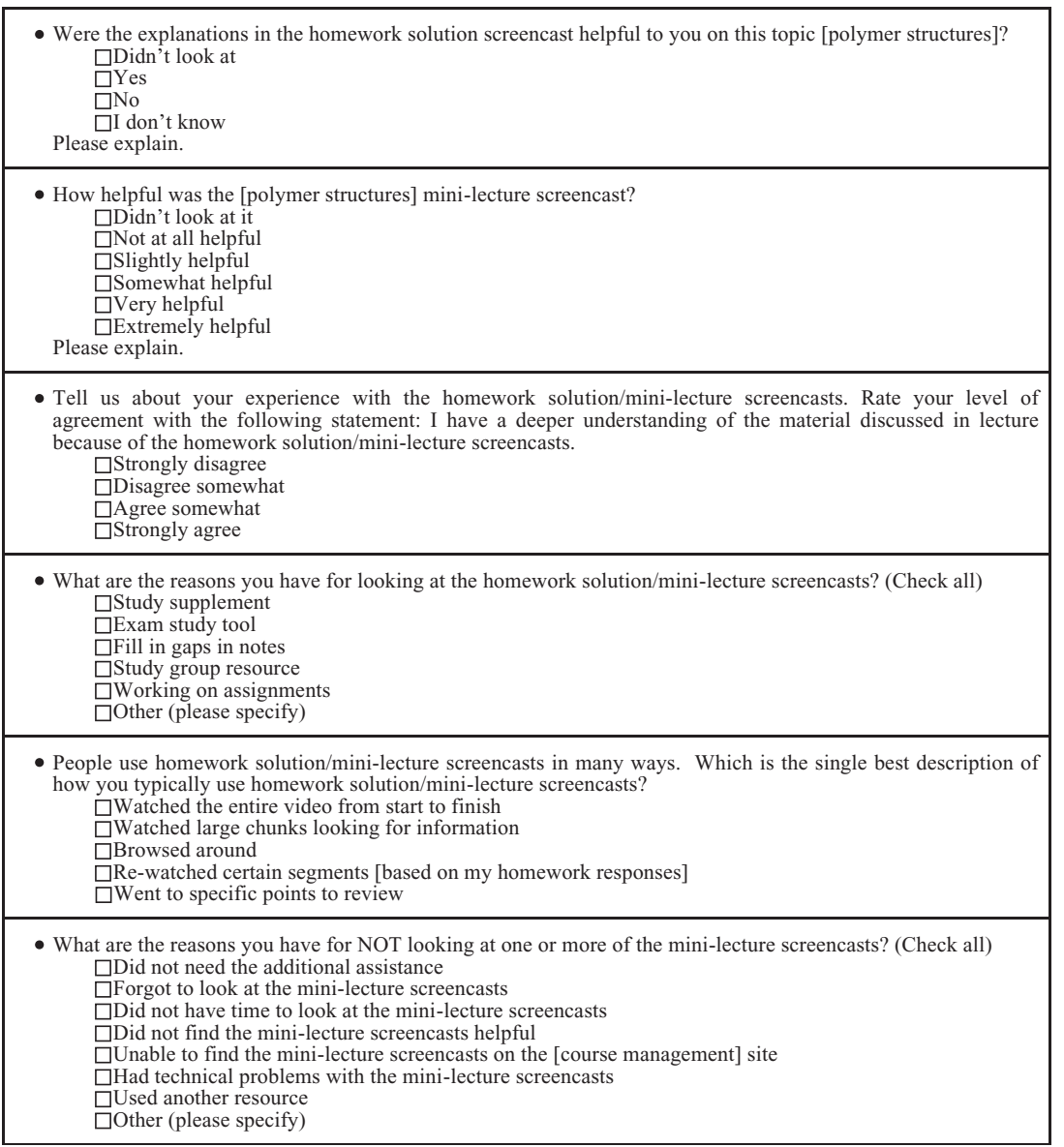

FIGURE 1. Survey questions.

reasons for using the screencasts, as well as their preferred strategies or typical use of screencasts. In the former case, students could mark as many reasons as applicable, while in the latter case, they were asked to choose the one response most typical of their screencast use. Finally, the survey also explored reasons students gave for not using the screencasts, with responses included in Figure 1.

\section{Sample}

For all demographic, usage, and performance measures, data were available for the entire population of students enrolled in the course $(N=397$, combining the 2008 and 2009 terms). However, survey data were available only for a subset of this student population $(n=262)$. For both semesters, the survey response rate was over $65 \%$ (i.e., $68 \%$ in the former term and $66 \%$ in the latter term). Because survey participation was optional, students self-selected into the sample. Further, not all students who took the survey responded to 
every question, which resulted in the potential for additional non-response bias per each question asked.

In general, the sample of students who responded to the online survey is representative of the underlying class population (in terms of gender, citizenship status, academic level, and choice of major). However, for several of the survey questions used in the present analyses, the responses somewhat over-represent Caucasian students, while under-representing Asian and historically under-represented minority (URM) students (AfricanAmerican, Hispanic, and Native-American students). Responses also tend to slightly over-represent students who are more likely to enter the class with higher SAT/ACT scores and higher GPAs, as well as students who both use the screencasts more frequently and receive higher final course grades. For example, the average number of Web site hits for all students in the class population is 23 compared with approximately 27 website hits (depending on the survey question analyzed) for the sample. As well, the mean final course grade is $83 \%$ for the population and $85 \%$ for the sample. The basic demographic breakdown for the class population is found on Table 1 . This course's demographic breakdown is within 3\% to $5 \%$ of the general trends for gender and race for this institution and nationally (National Science Board, 2010). Therefore, we can reasonably generalize these results to institutions with similar student populations.

\section{DataAnalyses}

Statistical investigation, using PASW Statistics 18 software (www.spss.com), began with analysis of all the demographic variables in relation to screencast usage, survey responses, and course performance, with gender and major standing out as most pertinent to this paper's analyses. Descriptive analyses of the online survey data included the helpfulness of screencasts to students and their use of them (e.g., reasons for using the tools and typical strategies for this use). Statistical tests determined the significance of relationships between students' strategies for using screencasts and the frequency of screencast use (i.e., number of Web site hits) and course performance (e.g., homework grade). Tests also explored whether strategic use was significantly related to student perceptions of having gained a deeper understanding of course material. Where appropriate, these results are reported in relation to homework solution and mini-lecture screencasts. Unless otherwise noted, Kruskal-Wallis $H$ nonparametric tests were chosen to accommodate the unequal sample size of subgroups and limitations due to small sample size for some of the subgroups. Ordinal data was also analyzed using this test. Mann Whitney $U$ post hoc tests located the significance reported in the Kruskal-Wallis test. Holm's sequential Bonferroni correction then determined significance levels for these post-hoc tests. All assumptions required of the Kruskal-Wallis $H$ test (and subsequent Mann Whitney $U$ tests) were met for each of the variables involved in these tests, e.g., mutually independent observations and samples from populations which follow the same continuous distribution. The chi square test of independence determined significance in relationships between categorical variables, e.g., strategies for using homework solution screencasts and several demographic categories (gender, race/ethnicity, citizenship, academic level, and major). All chi square tests included Cramér's $V$ as a measure of association between the aforementioned nominal variables. All analyses used data from both terms.

We next conducted a case study of performance on one particular exam question dealing with polymer structures. We focused on those students who entered the course with the least experience working with the concepts presented throughout the semester: the Industrial and Operations Engineers (IOEs). The case study sought to explore trends in 
TABLE 1

Student Background Characteristics for Fall 2008 and Winter 2009

\begin{tabular}{|c|c|c|c|c|}
\hline & \multicolumn{2}{|c|}{ Fall 2008} & \multicolumn{2}{|c|}{ Winter 2009} \\
\hline & Number & Percentage & Number & Percentage \\
\hline \multicolumn{5}{|l|}{ Sex } \\
\hline Males & 165 & 75.3 & 130 & 73.0 \\
\hline Females & 54 & 24.7 & 48 & 27.0 \\
\hline Total & 219 & 100.0 & 178 & 100.0 \\
\hline \multicolumn{5}{|l|}{ Race/Ethnicity } \\
\hline Caucasian & 141 & 64.4 & 96 & 53.9 \\
\hline African American & 6 & 2.7 & 14 & 7.9 \\
\hline Asian & 39 & 17.8 & 28 & 15.7 \\
\hline Hispanic & 2 & 0.9 & 14 & 7.9 \\
\hline Native American & 1 & 0.5 & 2 & 1.1 \\
\hline None $^{\mathrm{a}}$ & 30 & 13.7 & - & - \\
\hline Not indicated & - & - & 24 & 13.5 \\
\hline Total & 219 & 100.0 & 178 & 100.0 \\
\hline \multicolumn{5}{|l|}{ Major } \\
\hline Aerospace (AERO) & 60 & 27.4 & 36 & 20.2 \\
\hline Chemical (ChE) & 49 & 22.4 & 45 & 25.3 \\
\hline $\begin{array}{l}\text { Nuclear eng. \& radiological } \\
\text { sciences (NERS) }\end{array}$ & 19 & 8.7 & 9 & 5.1 \\
\hline $\begin{array}{l}\text { Industrial and operations } \\
\quad(\mathrm{IOE})\end{array}$ & 53 & 24.2 & 60 & 33.7 \\
\hline Material science (MSE) & 9 & 4.1 & 5 & 2.8 \\
\hline $\begin{array}{l}\text { Other engineering } \\
\text { (mechanical, civil, etc.) }\end{array}$ & 26 & 11.9 & 22 & 12.4 \\
\hline Other (non-engineering) & 3 & 1.4 & 1 & 0.6 \\
\hline Total & 219 & 100.0 & 178 & 100.0 \\
\hline \multicolumn{5}{|l|}{ Academic level } \\
\hline Senior & 59 & 26.9 & 76 & 42.7 \\
\hline Junior & 101 & 46.1 & 75 & 42.1 \\
\hline Sophomore & 59 & 26.9 & 26 & 14.6 \\
\hline Freshmen & - & - & 1 & 0.6 \\
\hline Total & 219 & 100.0 & 178 & 100.0 \\
\hline \multicolumn{5}{|l|}{ Citizenship status } \\
\hline U.S. citizen & 184 & 84.0 & 156 & 87.6 \\
\hline Permanent resident & 13 & 5.9 & 9 & 5.1 \\
\hline Non-resident & 22 & 10.0 & 13 & 7.3 \\
\hline Total & 219 & 100.0 & 178 & 100.0 \\
\hline \multicolumn{5}{|l|}{ Cumulative GPA ${ }^{\mathrm{b}}$} \\
\hline $4.0-3.6$ & 48 & 21.9 & 31 & 17.4 \\
\hline $3.5-3.0$ & 93 & 42.5 & 73 & 41.0 \\
\hline $2.9-2.6$ & 48 & 21.9 & 40 & 22.5 \\
\hline $2.5-2.0$ & 24 & 11.0 & 29 & 16.3 \\
\hline 1.9 and below & 6 & 2.7 & 5 & 2.8 \\
\hline Total & 219 & 100.0 & 178 & 100.0 \\
\hline
\end{tabular}

Note. - indicates data were not available or $n=0$.

a Students self-identifying as "none of the above."

b Average cumulative GPA: Fall 2008, 3.18; Winter 2009, 3.09. 
student responses to the polymer structures exam question, as well as to quantitatively test (using nonparametric Mann-Whitney $U$ and correlations) whether students who used the polymer structures screencasts more frequently and who reported that they gained a deeper understanding from this use were better able to demonstrate an understanding of the concepts entailed by the polymer structures exam question. In this part of the study, all quantitative analyses used data from one or both terms. Correlations were run to identify significant trends in the relationships between various types of screencast use and scores on the polymer structures exam question. These correlations were also run separately for each major group to determine significant differences in potential to gain (in terms of performance) by screencast use. The Mann-Whitney $U$ test was then used to check for significant differences in levels of deeper understanding acquired from screencast use when comparing high- and low-scoring students. For all statistical tests, unless otherwise noted, a $p$ value of 0.05 or less was required to determine significance.

Finally, to further understand students' motivations and perceptions, we examined the reasons they reported for non-use of screencasts despite the performance benefits of using them. After providing brief descriptive analysis, we present the results of independent samples $t$-tests for significant differences in course performance between those who do and do not report various reasons for non-use of the screencasts. These analyses allow us to explore whether students' perceptions of their need for the screencasts matches their actual need, as indicated by their final course grade.

\section{RESULTS}

\section{How Do Students Use the Screencasts and Perceive Their Helpfulness?}

In terms of the helpfulness of screencasts, the results of our online survey agree with other studies (Falconer et al., 2009). We find that in general students perceive these tools as helpful. For example, nearly $90 \%$ of those who responded to the survey and viewed the homework solution screencast on polymer structures $(n=142)$ indicated that the explanations were helpful. One Winter 2009 student said:

I felt they were extremely helpful, and much more extensive study tools than normal written homework solutions and lecture slides. The fact that the screencasts can be downloaded and played on iPods make them very convenient, and I hope that more professors begin using this technology.

Homework solution screencasts While these general impressions are valuable, we wanted to further examine how students use the 12 or 13 homework solution screencasts that were created over the course of our study, as well as to examine students' reasons for using them. When respondents were asked to select all the reasons why they viewed homework solution screencasts, they most commonly cited "exam study tool" and "study supplement," as noted by $89 \%$ and $76 \%$ of respondents, respectively (Table 2). One Winter 2009 student wrote that these screencasts assisted with exam preparation by helping the student "to better understand problems that I did wrong and understand why I did them wrong. This also helped solidify the overall concepts for me thus helping me prepare for exams and quizzes." This response implies that the student appreciated the screencasts because they addressed a particular aspect of his or her competency in materials science. This individual's comment is representative of the $92 \%$ of respondents who indicated having a deeper understanding of the material discussed in lecture because of the homework solution screencasts. 
TABLE 2

Reasons for Using Homework Solution and Mini-Lecture Screencasts

\begin{tabular}{lccccc}
\hline & \multicolumn{2}{c}{$\begin{array}{c}\text { Homework solution screencasts } \\
(n=209)\end{array}$} & & \multicolumn{2}{c}{$\begin{array}{c}\text { Mini-lecture } \\
\text { screencasts }(n=197)\end{array}$} \\
\cline { 2 - 3 } \cline { 5 - 6 } & Number & Percentage & & Number & Percentage \\
\hline Exam study tool & 185 & 89 & & 159 & 81 \\
Study supplement & 159 & 76 & & 163 & 83 \\
Working on assignments & 60 & 29 & & 86 & 44 \\
Fill in gaps in notes & 53 & 25 & & 74 & 38 \\
Study group resource & 15 & 7 & & 10 & 5 \\
\hline
\end{tabular}

TABLE 3

Strategies for Using Homework Solution and Mini-Lecture Screencasts

\begin{tabular}{|c|c|c|c|c|}
\hline & \multicolumn{2}{|c|}{$\begin{array}{l}\text { Homework solution screencasts } \\
\qquad(n=209)\end{array}$} & \multicolumn{2}{|c|}{$\begin{array}{c}\text { Mini-lecture } \\
\text { screencasts }(n=196)\end{array}$} \\
\hline & Number & Percentage & Number & Percentage \\
\hline $\begin{array}{l}\text { Watched entire video from start } \\
\text { to finish }\end{array}$ & 68 & 33 & 129 & 66 \\
\hline $\begin{array}{l}\text { Re-watched certain segments based on } \\
\text { my homework responses }\end{array}$ & 54 & 26 & 10 & 5 \\
\hline Went to specific points to review & 40 & 19 & 24 & 12 \\
\hline $\begin{array}{l}\text { Watched large chunks looking for } \\
\text { information }\end{array}$ & 29 & 14 & 18 & 9 \\
\hline Browsed around & 18 & 9 & 15 & 8 \\
\hline
\end{tabular}

When asked to indicate "Which is the single best description of how you typically use homework solution screencasts?" (choosing from a list of five options; Table 3), the two most commonly cited strategies were "watched the entire video from start to finish" (noted by 33\% of respondents) and "re-watched certain segments based on homework responses" (26\%). The amount of time required to watch a homework solution screencast from start to finish varied based on the number of assigned homework problems. Typically these screencasts ranged from 10 to 15 minutes for explanations of between 5 and 8 assigned homework problems.

Interestingly, while the vast majority of respondents recognized the benefit of the homework solution screencasts, significant differences were found in overall screencast use according to students' preferred strategies for using these screencasts, $\chi^{2}(4, n=209)=$ $14.750, p=0.005$. More specifically, students who reported that they watched the homework solution screencasts from start to finish viewed the screencasts at significantly higher rates than those who reported that they browsed around $(z=-2.76, p$ $=0.006)$, went to specific points to review $(z=-2.92, p=0.004)$ and re-watched certain segments based on homework responses $(z=-2.60, p=0.009$; see Table 4$)$. Note that the students who watched the homework solution screencasts from start to finish were also more likely to be among those with the lowest homework grades compared with students with all other preferred ways of using these screencasts, but this finding was not significant. Since homework solution screencasts were available after the assignment deadline, these students may have been increasingly motivated to watch the screencasts in their 
TABLE 4

Screencast Use (Number of Web site Hits) by Preferred Strategy for Using Homework Solution Screencasts in Fall 2008 and Winter 2009 (Mann-Whitney U)

\begin{tabular}{lcccc}
\hline Strategies compared & $z$ & Mean rank & $n$ & $p^{\mathrm{a}}$ \\
\hline $\begin{array}{l}\text { Watched entire screencast from } \\
\text { start to finish vs. browsed around }\end{array}$ & -2.76 & 47.32 vs. 29.08 & 68 vs. 18 & 0.006 \\
$\begin{array}{l}\text { Watched entire screencast from. } \\
\begin{array}{l}\text { start to finish vs. went to specific } \\
\text { points to review }\end{array}\end{array}$ & -2.92 & 61.24 vs. 43.04 & 68 vs. 40 & 0.004 \\
$\begin{array}{l}\text { Watched entire screencast from. } \\
\text { start to finish vs. re-watched certain }\end{array}$ & -2.60 & 68.91 vs. 52.17 & 68 vs. 54 & 0.009 \\
segments & & & & \\
\hline
\end{tabular}

a Significance according to the Mann-Whitney $U$ post hoc test with Holm's sequential Bonferroni correction.

entirety because of the low grades they received. For instance, one Fall 2008 student said, "I got things wrong and wanted to know how to fix them." This remark suggests that students who did poorly on the homework recognized the value of the screencasts for raising their competency with particular topics. Students performing higher on the homework tended to have re-watched certain segments or watched large portions of the homework solution screencasts. Since these approaches indicate a more targeted way of using the screencasts, this trend suggests that higher achieving students are likely to spend less time using screencasts by focusing only on specific issues or misconceptions related to the homework. Students with lower homework grades reported having watched more of the screencasts to bolster their understanding, while students with higher grades focused on the concepts they missed. Thus, our data suggests that both high- and low-achieving students use screencasts strategically based upon their own needs. This finding is comparable to the results of Owston, Lupshenyuk \&Wideman (2011), who reported that high achievers tended to watch lecture recordings only once and particular sections multiple times. In comparison, Owston et al. noted that lower achieving students were more likely to watch this supplementary resource multiple times.

Using the chi square test of independence, we also examined the relationship between strategies for viewing homework solution screencasts and membership in various demographic groups, e.g., race/ethnicity, gender, citizenship, academic level, and major. The only statistically significant differences across the preferred strategies were found for gender, $\chi^{2}(4, n=209)=12.09, p=0.016$. Using Cramér's $V$, a modest effect size was found for this relationship: $V=0.241, p=0.017$. Accordingly, males $(n=147)$ were slightly more likely than females $(n=62)$ to have watched the entire screencast from start to finish (35\% of males, $26 \%$ of females). As well, males were more likely to have watched large portions looking for information ( $17 \%$ of males, $7 \%$ of females). In turn, $40 \%$ of females reported having re-watched certain segments based on homework responses, while only $20 \%$ of males reported this. Males and females were roughly equally likely to have browsed around and gone to specific points to review. These differences in gender may actually be attributed to the fact that females typically performed significantly better on homework ( $88.9 \%$ mean grade) than male students 
(84.3\%), Mann Whitney $U(z=-2.941, p=0.003)$, with mean rank of 189 for males $(n=295)$ and 228 for females $(n=102)$. In addition, female students $(n=81)$ were significantly more likely to be both Chemical Engineers (ChEs) and Industrial and Operations Engineers (IOEs) than male students $(n=222)$, who were more likely to be Aerospace Engineers (AEROs), $\chi^{2}(2, n=303)=16.800, p=0.000$. It is noteworthy that ChEs and IOEs typically performed better on homework assignments (means of $88.3 \%$ and $87.1 \%$, respectively) in comparison to AEROs, who typically earned the lowest average homework grades (a mean of 84.3\%). While this finding was not significant, note that Mann Whitney $U$ tests of median homework grade for each of the three largest major groups found marginally significant differences between IOEs and AEROs $(p=0.021)$ and between ChEs and AEROs $(p=0.018)$. Significance levels required by Holm's sequential Bonferroni correction were slightly more stringent than the reported $p$-values.

Finally, we asked students to indicate their level of agreement with the statement "I have a deeper understanding of the material discussed in lecture because of the homework solution screencasts." In all, 92\% percent of students from both terms reported that they "strongly agree" or "agree somewhat" with this statement, indicating that the vast majority of students found these screencasts useful. Further, significant differences in deeper understanding were found across the various strategies for using the homework solution screencasts, $\chi^{2}(4, n=207)=11.26, p=0.024$. Students who reported that they watched the homework solution screencasts from start to finish were significantly more likely to report a deeper understanding from these screencasts than those students who reported that they went to specific points to review $(z=-2.966, p=0.003)$. Those who reported that they watched the homework solution screencasts in their entirety were also more likely to report that they gained a deeper understanding from the screencasts than those who reported that they browsed around $(z=-2.074, p=0.038)$ and re-watched certain segments based on homework responses $(z=-2.157, p=0.031)$; however, in both comparisons, significance levels did not meet the requirements of Holm's sequential Bonferroni correction (Table 5).

Mini-lecture screencasts In contrast to the homework solution screencasts, the minilecture screencasts were created in response to polls conducted by the instructor to determine which, if any, topics were unclear to the students. In addition, mini-lecture screencasts from previous semesters were made available to students at the beginning of each

TABLE 5

Deeper Understanding by Preferred Strategy for Using Homework Solution Screencasts in Fall 2008 and Winter 2009 (Mann-Whitney $U$ )

\begin{tabular}{lcccc}
\hline Strategies compared & $z$ & Mean rank & $n$ & $p^{\text {a }}$ \\
\hline $\begin{array}{l}\text { Watched entire screencast from start to finish } \\
\text { vs. went to specific points to review }\end{array}$ & -2.966 & 59.41 vs. 43.35 & 67 vs. 39 & 0.003 \\
$\begin{array}{l}\text { Watched entire screencast from start to finish } \\
\text { vs. re-watched certain segments }\end{array}$ & -2.157 & 66.34 vs. 54.38 & 67 vs. 54 & $0.031^{\text {b }}$ \\
$\begin{array}{l}\text { Watched entire screencast from start to finish } \\
\text { vs. browsed around }\end{array}$ & -2.074 & 45.45 vs. 33.89 & 67 vs. 18 & $0.038^{\text {c }}$ \\
\hline
\end{tabular}

${ }^{a}$ Significance according to the Mann-Whitney $U$ post hoc test. Significance levels determined using Holm's sequential Bonferroni correction.

${ }^{\mathrm{b}}$ Significance levels determined using Holm's sequential Bonferroni correction require $p=0.0125$ or less.

' Significance levels determined using Holm's sequential Bonferroni correction require $p=0.017$ or less. 
term, even if the new cohort of students did not specifically indicate that more information was desired for that particular topic. In Fall 2008, there were nine mini-lecture screencasts. In Winter 2009, the professor created 6 more screencasts for a total of 15 mini-lecture screencasts. Since the content of these screencasts was based on student-identified misconceptions, which students used these screencasts and the ways they viewed them may differ from homework solution screencasts.

As with homework solution screencasts, the overwhelming majority of students considered the mini-lecture screencasts to be helpful. For example, nearly $90 \%$ of students who responded to the survey and viewed the mini-lecture screencast on polymer structures $(n=126)$ indicated that the explanations were either "somewhat helpful," "very helpful," or "extremely helpful." In addition, the most commonly cited reasons for viewing these screencasts followed the same general trend as did the homework solution screencasts with responses of "exam study tool" and "study supplement" selected by $81 \%$ and $83 \%$ of students, respectively. However, students were more likely to use the mini-lecture screencasts to "fill in gaps in notes" (38\%) and to "work on assignments" (44\%) than they were for homework solution screencasts, an increase of $13 \%$ and $15 \%$, respectively. In addition, $5 \%$ of students reported using these screencasts as a "study group resource" (see Table 2)

Students were also asked "Which is the single best description of how you typically use mini-lecture screencasts?" The majority of students $(66 \%)$ responded that they "watched entire video from start to finish" (see Table 3). Typically, the mini-lecture screencasts were between 5 and 10 minutes in duration as compared with the longer homework solution screencasts. Students who reported that they watched the minilecture screencasts from start to finish were significantly more likely to have a higher number of Web site hits, $\left.\chi^{2}(4, n=196)=15.596, p=0.004\right)$ compared with those students who reported that they went to specific points in the mini-lecture screencasts to review $(z=-3.11, p=0.002)$, as well as compared with those students who reported that they browsed around $(z=-2.52, p=0.012$; see Table 6$)$.

Finally, we asked students to indicate their level of agreement with the statement "I have a deeper understanding of the material discussed in lecture because of the mini-lecture screencasts." In total, 90\% percent of students from both terms reported that they "strongly agree" or "agree somewhat" with this statement. These data suggest that the students who viewed the mini-lecture screencasts saw their benefit, most likely because the mini-lectures are relatively short and improve comprehension of materials science concepts. Significant differences in deeper understanding were found across the various strategies for using the mini-lecture screencasts, $\chi^{2}(4, n=193)=13.3, p=0.010$. Students

TABLE 6

Screencast Use (Number of Web site Hits) by Preferred Strategy for Using Mini-lecture Screencasts in Fall 2008 and Winter 2009 (Mann-Whitney $U$ )

\begin{tabular}{lcccc}
\hline Strategies compared & $z$ & Mean rank & $n$ & $p^{\mathrm{a}}$ \\
\hline $\begin{array}{l}\text { Watched entire screencast from start to finish } \\
\text { vs. went to specific points to review }\end{array}$ & -3.11 & 81.81 vs. 51.17 & 129 vs. 24 & 0.002 \\
$\begin{array}{l}\text { Watched entire screencast from start to finish } \\
\text { vs. browsed around }\end{array}$ & -2.52 & 75.49 vs. 46.80 & 129 vs. 15 & 0.012 \\
\hline
\end{tabular}

a Significance according to the Mann-Whitney $U$ post hoc test. Significance levels determined using Holm's sequential Bonferroni correction. 
who reported that they watched the mini-lecture screencasts from start to finish were significantly more likely to report a deeper understanding from the mini-lecture screencasts than students who reported that they browsed around $(z=-3.13, p=0.002)$. As well, students who reported that they re-watched certain segments of the mini-lecture screencasts were more likely to report a deeper understanding from the mini-lecture screencasts than students who reported that they browsed around $(z=-2.30, p=0.022)$. The significance of this pairwise comparison, however, did not reach the level required for full significance by Holm's sequential Bonferroni correction. It is interesting that students who took a less targeted approach by browsing around perceived fewer gains from the screencasts (see Table 7).

In summary, a majority of students found the homework solution and mini-lecture screencasts helpful. They used them most often as a study resource, particularly for exams. Despite similarities in the perceived usefulness of these two types of screencasts, the students took different approaches in using them. While the majority of students viewing homework solution screencasts watched them in their entirety, a substantial fraction only watched specific portions. In contrast, the vast majority of students watched the mini-lecture screencasts from start to finish, most likely due to their brevity. Students who watched the screencasts completely (either homework solution or mini-lecture) were also significantly more likely to report gaining a deeper understanding of the material. Overall, these findings show that students perceive screencasts as valuable; the next section describes the actual impact of viewing screencasts on student performance.

\section{Do Students' Perceptions of Screencast Helpfulness Match the Reality of Their Performance?}

Having explored students' perceptions of screencast helpfulness and their reasons and strategies for using these tools, we next examined whether these perceptions and uses translated into better scores on exam questions and better grades in the class overall. In other words, do students' perceptions of screencasts as helpful match the reality of their performance? We found that screencast use benefited students in terms of improved final grades and scores on particular exam questions. Furthermore, student perceptions that screencasts provide deeper understanding of course material is an accurate indication of students' actual performance. This agreement was particularly true for those students who entered the course least familiar with materials science content.

To begin, we briefly examined screencast use in connection with performance, as detailed in our previously published work (Pinder-Grover et al., 2011). There we

TABLE 7

Deeper Understanding by Preferred Strategy for Using Mini-lecture Screencasts in Fall 2008 and Winter 2009 (Mann-Whitney $U$ )

\begin{tabular}{lcccc}
\hline Strategies compared & $z$ & Mean rank & $n$ & $p^{\mathrm{a}}$ \\
\hline $\begin{array}{l}\text { Watched entire screencast from start to } \\
\text { finish vs. browsed around }\end{array}$ & -3.13 & 74.30 vs. 43.30 & 126 vs. 15 & 0.002 \\
$\begin{array}{l}\text { Re-watched certain segments vs. browsed } \\
\text { around }\end{array}$ & -2.30 & 16.80 vs. 10.47 & 10 vs. 15 & $0.022^{\mathrm{b}}$ \\
\hline
\end{tabular}

a Significance according to the Mann-Whitney $U$ post hoc test. Significance levels determined using Holm's sequential Bonferroni correction.

${ }^{\mathrm{b}}$ Significance levels determined using Holm's sequential Bonferroni correction require $p=0.0125$ or less. 
analyzed the impact of screencast usage in general, as indicated by the number of Web site hits, on performance, as indicated by the final course grade; we found a positive, significant correlation between screencast use and performance overall. However, results were mixed when this relationship was examined across various demographic subgroups. For both gender and citizenship, students appeared to benefit equally from screencast use, regardless of being male or female, U.S. citizen or not. For race/ethnicity and academic level, we found that while two groups of students (sophomores and historically under-represented minorities in engineering fields) at first appeared to have the most to gain from screencast use, their performance was actually more accurately explained by GPA, not screencast use. Most importantly, however, we found a significant effect for the impact of screencast use on performance across academic major. We focused our analysis on the three majors that comprise the largest portion of the student population: namely, Aerospace Engineering (AERO), Chemical Engineering (ChE), and Industrial and Operations Engineering (IOE). Of these groups, the $\mathrm{ChE}$ curriculum is most similar to Materials Science and Engineering (MSE), sharing a large number of analogous topics, and the IOE curriculum is the least similar, having no courses that address concepts covered in the particular MSE course under study. Prior to the introduction of screencasting in this course, IOEs as a group had the lowest final grades despite having academic indicators (e.g., GPA, SAT, ACT) comparable to the rest of the class. Once the screencasts were introduced, however, IOEs accessed these resources at the highest rates and were the only major group to show a statistically significant positive relationship between level of screencast use and final course grade. Thus, the findings of our previous work suggest that students whose academic backgrounds have prepared them the least for the course content (IOEs) may use screencasts more, perhaps due to their lack of familiarity and confidence related to the concepts, and that this screencast usage results in better performance overall. As part of this current study, we present a case study that focuses specifically on the performance of IOEs on one particular exam question in an attempt to achieve a more nuanced understanding of how the performance benefits of screencast use are connected to student perceptions of mini-lecture screencasts.

\section{Industrial and Operations Engineers: An Exam Performance Case Study}

Although we do not have pre-/post-measures in our research design, the statistical analysis of screencast use and course performance shows that students majoring in IOE show greatest improvement with the availability of supplemental resources. Since IOEs tended to use the screencasts more and their use of these resources mattered more in terms of their performance, the purpose of this case study is to look closely at how screencasts assisted the particular students who entered the MSE course with the least amount of background knowledge and experience pertaining to course content.

To further analyze the impact of the mini-lecture screencasts on the performance of IOEs, we focused on one concept, polymer structures. A polymer structures screencast was produced in response to student requests to clarify several polymer concepts, specifically focusing on the mechanical behavior of various types of polymers and how the atomic structure of the polymer molecule affects this behavior. In creating this screencast, the instructor coupled short oral reviews of the topic with schematics and Flash animations to illustrate the underlying physics. The polymer structures screencast was posted between the 
homework assignments and exam on the same subject. In this case study, we explored a final exam problem that focused directly on polymer structures to determine if students who viewed the screencasts more often than other students and perceived themselves to have gained deeper understanding from this viewing were better able to answer the exam question completely and correctly.

Having already established that all students gain (i.e., improve their overall final course grade) from the use of screencasts, we examined whether this positive relationship between screencast use and performance also held for the polymer structures final exam question. In general, we found modest yet statistically significant positive correlations between performance on the polymer structures exam question and all measures of screencast use. These results indicate that all students who use screencasts at greater frequency were more likely to perform better on the polymer structures exam problem. This more frequent use included general screencast use, the number of Web site hits $(r=0.272, p=$ $0.000, n=175)$, and use of the screencast specifically designed to address polymer structures $(r=0.240, p=0.001, n=175)$.

Further analyses examined whether this general relationship between use and performance persisted for students of all academic backgrounds. A split file was used to run the same set of correlations for each of the three largest major groups. As shown in Table 8, the positive significant correlation between use and performance was retained for only two of the majors: AERO and IOE. For these two groups, more frequent use of screencasts in general (number of Web site hits), and of the polymer structures screencast specifically, was significantly related to higher scores on the final exam problem on polymer structures. However, note that the magnitude and significance of the correlation was greater for IOEs - precisely the group we suggest has the most to gain from use of screencasts due to their relative lack of familiarity with course content at the start of the term.

Knowing that those IOEs who used screencasts at higher rates did in fact earn higher scores on the polymer structures final exam question, we next examined these students' perceptions of whether or not they gained a deeper understanding of the course material from their screencast use. We did so by inquiring whether or not they actually demonstrated this deeper understanding by way of their performance on the polymer structures final exam problem. Accordingly, we divided the IOE students into two roughly equal groups based on their score on the polymer structures exam problem. The low-scoring students earned between 0 and 11 points $(n=56)$, while highscoring students earned between 11.5 and 15 points ( $n=54)$. Using Mann-Whitney $U$, we tested for significant differences in these two groups' perceptions of their deeper

TABLE 8

Screencast Use and Performance on Final Exam Question One by Students' Major (Pearson Correlations)

\begin{tabular}{|c|c|c|c|c|c|}
\hline \multirow[b]{2}{*}{ Major } & \multirow[b]{2}{*}{$n$} & \multicolumn{2}{|c|}{$\begin{array}{l}\text { Number of Web site hits \& polymer } \\
\text { structure final exam question }\end{array}$} & \multicolumn{2}{|c|}{$\begin{array}{c}\text { Number of views of polymer } \\
\text { structure screencast (range }=0 \text { to } 5 \text { ) } \\
\text { \& polymer structure final exam question }\end{array}$} \\
\hline & & Correlation & Sig. & Correlation & Sig. \\
\hline AERO & 34 & $r=0.350^{*}$ & $p=0.042$ & $r=0.345^{*}$ & $p=0.046$ \\
\hline $\mathrm{ChE}$ & 45 & $r=0.123$ & $p=0.421$ & $r=0.177$ & $p=0.243$ \\
\hline $\mathrm{IOE}$ & 60 & $r=0.425^{\text {** }}$ & $p=0.001$ & $r=0.375^{\text {** }}$ & $p=0.003$ \\
\hline
\end{tabular}

${ }^{*} p<0.05 ;{ }^{* *} p<0.01$. 
understanding, which was measured using a four-point Likert scale that ranged from "strongly disagree" to "strongly agree." As shown in Table 9, those IOE students who, at the end of the term, reported that they "strongly agree" with the statement "I have a deeper understanding of the material because of the mini-lecture screencasts" were significantly more likely to receive high scores on the polymer structures exam problem. Conversely, those IOE students who chose only "agree somewhat" were significantly more likely to receive low scores $(z=-2.409, p=0.016)$. This same significant relationship between perceived deeper understanding and actual performance also held for performance generally, as measured by final course grade. Essentially, those IOE students who actually demonstrated deeper understanding, as evidenced by higher scores on the polymer structures exam problem, did in fact report (prior to taking the final exam) that they gained this deeper understanding, at least in part from use of the mini-lecture screencasts. These students saw a benefit to using the tools that improved not only their perception of increased understanding, but also their demonstrated competence regarding MSE concepts.

\section{Given the Benefits of Screencast Use, Why Would Students Choose Not ToUseThem?}

Given that screencasts are helpful to students and their use significantly improves course performance, it is noteworthy that a considerable number of students choose not to access them. Students in the Winter 2009 term (the only term in which the survey question pertaining to why students did not use screencasts was asked) made this choice despite knowing the performance benefits of the screencast use. Data from the previous term indicating these benefits were made available to Winter 2009 students near the beginning of the semester. We explored students' reasons for not using mini-lecture screencasts despite being informed about them. These reasons approximate students' perceptions of their own need for additional help in understanding various course concepts. We then tested for significance in the relationships between these reasons and students' course performance in order to determine whether students' perceived need for supplemental resources accurately reflected their actual need for these resources, as evidenced by lower final course grade. We find that the students' reasons for not using screencasts vary a great deal, and that the impact of non-use on their final grade depends on these factors.

Seventy-five students ( $42 \%$ of the 178 enrolled in Winter 2009) responded to the questions regarding reasons for not using mini-lecture screencasts. Of those who responded, 23 (32\%) reported more than one reason for not accessing these screencasts. The most common response was that a student "did not need the additional assistance" as reported by $57 \%$ of respondents. Table 10 gives the percentage of students indicating each of the reasons for not using the mini-lecture screencasts, along with the average final course

TABLE 9

Deeper Understanding by Scores on Final Exam Polymer Structures Question (Two Roughly Equal Groups) in Fall 2008 and Winter 2009 (Mann-Whitney U)

\begin{tabular}{lcccc}
\hline Comparison & $z$ & Mean rank & $n$ & $p^{\mathrm{a}}$ \\
\hline Low-scoring students vs. high-scoring students & -2.409 & 23.77 vs. 33.54 & 24 vs. 34 & 0.016 \\
\hline
\end{tabular}

a Significance according to the Mann-Whitney $U$ test. Holm's sequential Bonferroni correction not needed since analyses involved only two groups. 
TABLE 10

Reasons for Not Using Mini-Lecture Screencasts

\begin{tabular}{lccc}
\hline & \multicolumn{2}{c}{ Respondents $(n=75)$} & \\
\cline { 2 - 3 } Reasons & Number & Percentage & Mean final grade (\%) \\
\hline Did not need additional assistance & 43 & $57^{* *}$ & 87 \\
Forgot & 21 & $28^{*}$ & 83 \\
Did not have time & 22 & 29 & 85 \\
Did not find the screencast helpful & 3 & 4 & 86 \\
Unable to find the screencast & 1 & 1 & - \\
Had technical problems & 2 & 3 & 81 \\
Used another resource & 11 & 15 & 88 \\
\hline
\end{tabular}

*** $p<0.01 ; * p<0.05$ (significance level within each row).

Note; - Indicates $n=1$; therefore no mean is reported.

grade earned by those students who report each reason. The noted significance relates to independent sample $t$-tests (described below) used to determine whether mean final course grade differs significantly between those who did and did not indicate a particular reason for not using the mini-lecture screencasts. Thus, this significance is within each row, rather than across the seven rows in Table 10.

The motivations for not using mini-lecture screencasts were varied. Some students indicated an active decision based on their perception that they did not need the resource or that they could better understand the material with an alternate resource. Other motivations for not using screencasts imply neglect by way of forgetfulness, lack of time, or technological difficulty. We found, however, that it was the students who reported nonuse because they did not think that they needed the additional assistance who stand out compared to those with all other motivations for non-use. These students correctly perceived that they did not need the screencasts; they were significantly more likely to receive a higher final course grade $(M=87 \%, n=43)$ than students who did not indicate lack of need for the screencasts as a reason for non-use $(M=84 \%, n=32)$; independent samples $t$-test: $t(1,73)=-2.217, p=0.030$. Essentially, students who did not use the screencasts because they thought they did not need the extra help performed significantly better in the course than students who did not use the screencasts for other reasons. This shows that for this group of students, the screencasts provided no additional benefit. This is consistent with another study that found that higher achieving students viewed video resources less often than lower achieving students (Traphagan et al., 2010).

Besides not needing additional assistance, students offered various other reasons for not using mini-lecture screencasts. As previously noted, they may have chosen another resource instead of the screencasts; they may have simply forgotten or not found the time to take advantage of them. Students who reported non-use of the mini-lecture screencasts because they forgot were significantly more likely to have received a lower final course grade $(M=83 \%, n=21)$ than those who did not report this particular reason for non-use $(M=87 \%, n=54)$; independent samples $t$-test: $t(1,73)=2.629, p=0.010$. A subset of these forgetful students felt they did not need the additional assistance $(38 \%, n=8)$, suggesting that they did not accurately perceive their need. The lower average final grade for this subset suggests that they may have benefited more from screencast use than they originally thought. Had they not forgotten to use the resource, their final course grades might 
have been improved. These findings imply that forgetting to access the screencasts may be detrimental to student performance, regardless of perceived need.

Students who reported non-use of the screencasts due to not having time $(n=22)$ were also more likely to have received a lower final course grade than students who did not indicate this particular reason for not using screencasts; however, this performance difference was not significant. A subset of these students $(36 \%, n=8)$ reported both not having time to access the screencasts and not needing additional assistance. While interesting to note, it is difficult to postulate whether these trends indicate the value students place on the resource or simply reflect poor time management skills, especially given the lack of significance in this finding.

Finally, no significance was found for those who reported not using screencasts because they did not think they were helpful, could not find the screencasts in question, or experienced technical difficulty. Students who chose another resource in lieu of screencasts did not perform significantly better or worse than those who did not report this reason for non-use. This result is most likely due to the small $n$ 's for the subgroups involved in the analyses.

\section{SUMMARY}

We have shown that students in an introductory materials science and engineering course believed screencasts were helpful and used (or did not use) them for a variety of reasons. Most students reported watching screencasts in their entirety as a way to study for exams, and they also indicated that they obtained a deeper understanding of the material as a result of studying course concepts in this manner. That students used these resources in high numbers and persisted to watch them in their entirety supports the notion that overall students found the screencasts useful. Students who reported that they received a deeper understanding due to watching screencasts actually demonstrated more proficiency with the course material, as evidenced by their final course grades and performance on a specific exam question. This finding was particularly true for students with the least prior experience with the course content (i.e., students majoring in IOE). These students tended to use screencasts more and received higher grades in connection with this use. This finding suggests that the perceived helpfulness of the screencasts is justified, as student competency increases as a result of using them.

Finally, we have shown several reasons why students reported non-use of screencasts. Those who reported not using them because they did not need additional assistance may already have had a good grasp of the material; indeed, collectively these students demonstrated higher performance. Other students who forgot to use the screencasts or ran out of time performed less favorably. Perhaps this latter group did not reflect on their learning in a way that allowed them to thoroughly assess the potential performance enhancement from viewing screencasts.

\section{CONCLUSIONS AND FuTURE WORK}

These data demonstrate that screencasts are useful for explaining concepts and procedures. Screencasts promote a more active and voluntary form of learning because they present the course material in a manageable format; screencasts are brief, easy to use, and optimal. In this manner, screencasts have the potential to influence students' expectations regarding 
their ability to master the material (Barron and Hulleman, 2006). These data also suggest that screencasting offers additional exposure to important concepts for those students who enter a course with the least familiarity with the course material. This additional exposure can promote deeper understanding of course topics, thus leveling the playing field. An important next step is to determine the effect of screencasts on specific learning outcomes.

Another implication of these findings is that screencasting can be used in any course to shift the first exposure to particular concepts (Walvoord \& Anderson, 1998). For example, viewing screencasts on new topics or procedures can be assigned as homework prior to class meetings (Ellis, 2008). In this way, classroom time might be freed up to focus on application of concepts rather than on data-accumulation and the passive reception of information. This use could allow for more active forms of learning during times when instructors and students can interact in person. A remaining question is whether the benefits of screencasting are generalizable across other course formats (i.e., labs, computer programming, design courses, etc.), teaching styles, and institutional contexts.

Another interesting research direction would be to examine how screencasts can influence student motivation and self-efficacy. Self-efficacy (Bandura, 1994; Bandura, 1997 ) and the related expectancy-value theory (Eccles \& Wigfield, 2002; Wigfield \& Eccles, 2000) provide a useful framework for understanding student motivation, both to do well in a particular course and to use additional resources such as screencasts. Self-efficacy, students' beliefs about their academic capabilities, has been shown to be strongly linked to their motivation to achieve (Zimmerman, 2000; Hutchison, Follman, Sumpter \& Bodner, 2006). That is, the self-efficacious student is more likely to undertake difficult tasks, work harder, and persist longer at these tasks than a student with low self-efficacy. One could also examine whether the use of screencast mini-lectures can give students with low self-efficacy a greater chance to succeed with the material. However, academic motivation is affected not only by each student's level of self-efficacy; it also varies more generally in terms of strength or intensity, and whether it is focused intrinsically or extrinsically (Ryan \& Deci, 2000). By creating and publishing screencasts judiciously, it may be possible to promote more active and voluntary forms of learning that can enhance the intrinsic rewards experienced by students. By voluntarily using screencasts that break concepts down into manageable pieces, students might enhance their persistence and performance related to unfamiliar topics. Activities that are initially extrinsically motivated, such as watching screencasts for the purpose of getting a better grade, can be shifted over (or internalized) so that they become more intrinsically motivated when the student is given a sufficient degree of autonomy and the experience of competence at these activities (Ryan \& Deci, 2000). Initial findings strongly suggest that students will more likely use screencasts if they understand how the screencasts support their own competence in a particular topic. In other words, students will be more likely to value the screencasts (and therefore motivated to use them voluntarily) if they expect that these tools will enhance their competence and ultimately their performance. It remains for future work to clearly demonstrate this connection using established measures of self-efficacy and motivation, as well as within the context of expectancy-value theory.

\section{ACKNOWLEDGEMENTS}

We gratefully acknowledge Cindy Finelli, Jacque Eccles, and Allyson Bregman for insightful discussion and feedback on our manuscript. In addition, we appreciate the University of Michigan's Center for Research on Learning and Teaching (CRLT), which 
administers the Investigating Student Learning grants competition, and both CRLT and the College of Engineering which provided financial support for this research project.

\section{REFERENCES}

Bandura, A. (1994). Self-efficacy. In V. S. Ramachaudran (Ed.), Encyclopedia of human behavior ,4, 71-81. New York: Academic Press. (Reprinted in H. Friedman [Ed.], Encyclopedia of mental health. San Diego: Academic Press, 1998).

Bandura A. (1997). Self-Efficacy: The exercise of control. New York: Freeman.

Barron, K.E., \& Hulleman, C.S. (2006). Is there a formula to help understand and improve student motivation? In B. K. Saville, T. E. Zinn, S. A. Meyers, \& J. R. Stowell (Eds.), Essays from excellence in teaching, 2006 (chap. 8). Retrieved May 25, 2012 from the Society for the Teaching of Psychology Web site: http://teachpsych.org/resources/e-books/eit2006/ eit2006.pdf

Betty, P. (2009). Assessing homegrown library collections: Using Google Analytics to track use of screencasts and Flash-based learning objects. Journal of Electronic Resources Librarianship, 21(1), 75-92.

Bongey, S., Cizadlo, G. \& Kalnbach, L. (2006). Explorations in course-casting: Podcasts in higher education. Campus-Wide Information Systems, 23(5), 350-367.

Brown-Sica, M., Sobel, K. \& Pan, D. (2009). Learning for all: Teaching students, faculty, and staff with screencasting. Public Services Quarterly, 5(2), 81-97.

Copley, J. (2007). Audio and video podcasts of lectures for campus-based students: Production and evaluation of student use. Innovations in Education and Teaching International 44(4), 387-399.

Cramer, K., Collins, K., Snider, D. \& Fawcett, G. (2006). Virtual lecture hall for in-class and online sections: A comparison of utilization, perceptions and benefits, Journal of Research on Technology in Education, 38(4), 371-381.

Dey, E., Burn, H., \& Gerdes, D. (2009). Bringing the classroom to the web: Effects of using new technologies to capture and deliver lectures. Research in Higher Education, 50, 377-393.

Eccles J. \&Wigfield, A. (2002). Motivational beliefs, values, and goals. Annual Review of Psychology. 53, 109-32.

Ellis, C. (2008). You can't do that in a classroom!: How distributed learning can assist in the widespread adoption of hybrid learning strategies. In J. Fong, R. Kwan \& F.L. Wan (Eds). Hybrid Learning and Education, Proceedings, Book Series: Lecture Notes in Computer Science 5169, 1-16, Springer: Berlin.

Evans, D. (2011) Using embryology screencasts: A useful addition to the student learning experience? Anatomical Sciences Education. 4 (2), 57-63.

Falconer, J., deGrazia, J., Medlin, W. \& Holmberg, M. (2009). Using screencasts in ChE courses. Chemical Engineering Education, 43(4), 302-305.

Gardner, J. \& Jeon, T. (2010). Creating task-centered instruction for web-based instruction: Obstacles and solution. Journal of Educational Technology Systems, 38(1), 21-34.

Grabe, M. \& Christopherson, K. (2008). Optional student use of online lecture resources: Resource preferences, performance and lecture attendance. Journal of Computer Assisted Learning, 24, 1-10.

Harpp, D., Fenster, A., Schwarcz, J., Zorychta, E., Goodyer, N., Hsiao,W. \& Parente, J. (2004). Lecture retrieval via the web: Better than being there? Journal of Chemical Education, 81(5), 688-690. 
Hove, C. \& Corcoran, K. (2008). If you post it, will they come? Lecture availability in introductory psychology. Teaching of Psychology, 35(2), 91-95.

Hutchison, M., Follman, D., Sumpter, M. \& Bodner, G., (2006). Factors influencing the selfefficacy beliefs of first-year engineering students. Journal of Engineering Education, 96(1), 39-47.

Lee, M., Pradhan, S. \& Dangarno, B. (2008). The effectiveness of screencasts and cognitive tools as scaffolding for novice object-oriented programmers. Journal of Information Technology Education, 7, 61-80.

McGarr, O. (2009). A review of podcasting in higher education: Its influence on the traditional lecture. Australasian Journal of Educational Technology, 25(3), 30-321.

McGrann, R. (2005). Enhancing engineering computer-aided design education using lectures recorded on the PC. Journal of Educational Technology Systems, 34(2), 165-175.

Millunchick, J. M. (2008). Example of a Mini-Lecture Screencast on Dislocations. Retrieved from jmmg5.engin.umich.edu/dislocation/dislocations.html

Millunchick, J. M. (2009). Example of a Homework Solution Screencast. Retrieved from jmmg5.engin.umich.edu/hw04/hw04.html

National Science Board. (2010). Science and Engineering Indicators 2010. Arlington, VA: National Science Foundation (NSB 10-01).

Owston, R., Lupshenyuk, D. \&Wideman, H. (2011). Lecture capture in large undergraduate classes: Student perceptions and academic performance. Internet and Higher Education. 14(4), 262-268.

Pinder-Grover, T., Green, K., \& Millunchick, J.M. (2011). The efficacy of screencasts to address the diverse academic needs of students in a large lecture course. Advances in Engineering Education, 2 (3). Retrieved from http://advances.asee.org/vol02/issue03/09.cfm

Pinder-Grover, T., Millunchick, J. M., Bierwert, C., \& Shuller, L. (2009a). Leveraging screencasts to strategically clarify unclear materials science concepts. Paper presented at American Society for Engineering Education, Austin TX. Retrieved from http://www.asee.org/search/ proceedings

Pinder-Grover, T., Millunchick, J. M., Bierwert, C., \& Shuller, L. (2009b). The efficacy of screencasts on diverse students in a large lecture course. Paper presented at American Society for Engineering Education, Austin TX. Retrieved from http://www.asee.org/ search/proceedings

Rose, K. (2009). Student perceptions of the use of instructor-made videos in online and faceto face classes. MERLOT Journal of Online Learning and Teaching, 5(3) Retrieved from http://jolt.merlot.org/vol5no3/rose_0909.htm

Ryan, R. \& Deci, E. L. (2000). Intrinsic and extrinsic motivations: Classic definitions and new directions. Contemporary Educational Psychology, 25, 54-67.

Sugar, W., Brown, A. \& Luterbach,K. (2010). Examining the anatomy of a screencast: Uncovering common elements and instructional strategies. International Review of Research in Open Eं Distance Learning, 11(3), 1-19.

Traphagan, T., Kucsera, J., \& Kishi, K. (2010). Impact of class lecture webcasting on attendance and learning. Educational Technology Research and Development, 58 (1), 19-37.

Walvoord, B.F., \& Anderson, V.J. (1998). Effective grading. San Francisco: Jossey-Bass.

Wigfield, A. \& Eccles, J. (2000).Expectancy-value theory of achievement motivation. Contemporary Educational Psychology, 25, 68-81.

Zhu, E., \& Bergom, I. (2007). Lecture capture: A guide for effective use (CRLT Occasional Paper, No. 27). University of Michigan, Center for Research on Learning and Teaching. Retrieved from http://www.crlt.umich.edu/publinks/resources/occaisonal 
Zimmerman, B. (2000) Self-Efficacy: An essential motive to learn. Contemporary Educational Psychology, 25, 82-91.

\section{Authors}

Katie R. Green was a research associate in the College of Education's Curriculum, Teaching, and Educational Policy program, Michigan State University. She currently is a research associate at the University of Michigan; katierae@umich.edu.

Tershia Pinder-Grover is an assistant director at the Center for Research on Learning and Teaching (CRLT) and CRLT in Engineering, University of Michigan, 1071 Palmer Commons, 100 Washtenaw Ave., Ann Arbor, Michigan, 48109; tpinder@umich.edu.

Joanna Mirecki Millunchick is a professor of materials science and engineering and a faculty associate of the Center of Research on Learning and Teaching in Engineering, University of Michigan, 2300 Hayward Street, Ann Arbor MI 48109-2136, joannamm@ umich.edu. 